\title{
SOUTHERN DOGFACE BUTTERFLY NEAR WEYBURN, SK
}

\section{Martin Bailey}

306 - 435 2nd Street

Weyburn, SK S4H OV4

Around $11: 00 \mathrm{~h}$ on the morning of July 14, 2016, we - Martin Bailey and Carol Bjorklund - stopped on a gravel road just south of Nickle Lake Dam at S13-7-14W2 near Weyburn, SK to look at birds and butterflies.

Amongst the fluttering panorama of Wood Nymph, Skippers, Crescents, Cabbage White and Clouded Sulphur, Martin saw a sulphur butterfly that was larger, with a clear bright yellow ventral side, unlike the Clouded Sulphurs that were more of a lemon yellow. The ventral forward wing was pointed and sharp, not rounded like Clouded Sulphur.

Carol saw the dorsal side of the wings. The forewing was bright, clear yellow, with a wide, black, blocky and jagged outer rim. Inside the forewing was a black spot. The hind wing had a very narrow dark black band. The shape of the wings was pointed and sharp.

When the butterfly disappeared, Martin retrieved his Brock, J.P. and Kenn Kaufman (2003) "Butterflies of North America." It was obvious that the butterfly was a male Dogface.

We know of no records for Saskatchewan. This may be the first.

Royer, R.A., (2003) "Butterflies of North Dakota," where Dog Face Zerene cesonia is "an occasional stray" found in Slope and Cass Counties, ND.

P. Klassen et.al. (1989) "The Butterflies of Manitoba" with two records of Dogface Colias cesonia = Zerene cesonia.
C.D. Bird et. al. (1995) "Alberta Butterflies" with one record of Dog Face Zerene cesonia.

R.S. Layberry et. al. (1998) "The Butterflies of Canada" which lists three records for Manitoba and one for Alberta of Southern Dogface Zerene cesonia.

Scott, J.A. (1986) "The Butterflies of North America" where he lists Dog Face Colias cesonia as far north as Manitoba.

\section{Additional Information of Interest:}

The Southern Dogface is a new butterfly for Saskatchewan and represents only the fourth record for prairie Canada that I am aware of. That said, this is an irruptive species that regularly makes northward migrations, similar to the more familiar painted lady, though these flights only rarely reach Canada and then usually in southern Ontario.

The key observation noted was the very pointed forewing. This would distinguish it from the Mexican Yellow - another very rare stray that is superficially similar to the Southern Dogface, and for which there is one previous Saskatchewan record. The very common Clouded Sulphur is quite variable but generally smaller and with more rounded wings. While a variant of clouded sulphur might share many characteristics with the Dogface, the wing shape alone would certainly exclude it.

- Mike Gollop, Saskatoon, SK

\section{INTRODUCING EMILY PUTZ}

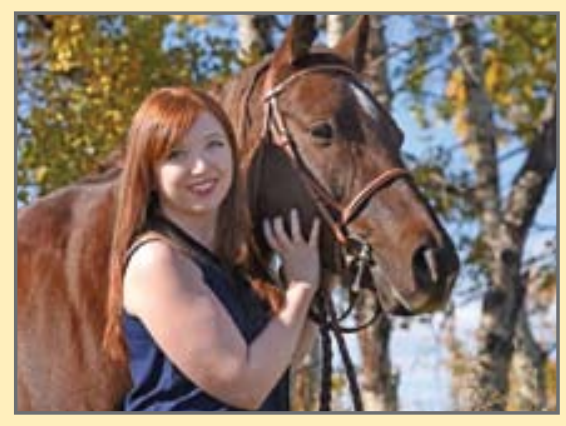

Emily was born and raised in Regina, Saskatchewan and has always had a fascination with the outside world. Her interest in nature started when she was young - growing up, most of her time was spent writing in nature journals, bird watching, gardening, and exploring different areas of Saskatchewan each summer on father-daughter trips. Emily knew that her interest was always to pursue a career in biology and she completed her degree in biology with a concentration in ecology and environmental biology from the University of Regina. She has been lucky to have had great opportunities to work with a number of different species including the SOS target species, time spent in South Africa doing species surveys, and this past summer working on the Piping Plover Project as well as doing population and habitat assessments for Chestnut Lamprey. Emily's spare time is spent hiking, reading, horseback riding, and spending time with her zoo-at-home, including a very affectionate dog, cat, rabbits and a horse. She first joined the Nature Saskatchewan team in 2014 as a habitat stewardship summer assistant and she is very excited to once again be back, this time in the position of Rare Plant Rescue (RPR) coordinator. $\ell$ 